\title{
Review on globularization of titanium alloy with lamellar colony
}

\author{
Jian Zhang, Hongwei $\mathrm{Li}^{*}$, and Mei Zhan
}

State Key Laboratory of Solidification Processing, Shaanxi Key Laboratory of Precision Forming Technology and Equipment, School of Materials Science and Engineering, Northwestern Polytechnical University, PO Box 542, Xi'an 710072, PR China

Received: 2 February 2020 / Accepted: 21 April 2020

\begin{abstract}
The globularization of titanium alloy with lamellar colony during hot working is an important way to obtain fine and homogeneous microstructure which has excellent mechanical properties. Because of its great technological importance, globularization has captured wide attention and much research. This paper conducts a systematic study on state of art on globularization of titanium alloy, which mainly includes globularization mechanism, prediction model and the effects of hot-working parameters and microstructure parameters. Firstly, the shortcomings of the well-known globularization mechanisms (dynamic recrystallization, boundary splitting, shearing mechanism and termination migration) were summarized. Moreover, the comparison and analysis of prediction models were accomplished through tabular form. In addition, the effects of hot-working parameters (strain, strain rate, temperature) and microstructure parameters (alpha/beta interface, geometry necessary dislocation and high temperature parent beta phase) were systematically summarized and analyzed. Meanwhile, this study also explores those difficulties and challenges faced by precise control on globularization. Finally, an outlook and development tendency of globularization of titanium alloy are also provided, which includes microstructure evolution of three-dimensional lamellar alpha, the relationship between lamellar colony and mechanical properties and the effect of severe plastic deformation on globularization.
\end{abstract}

Keywords: Titanium alloy / Lamellar colony / Globularization / Prediction model

\section{Introduction}

Titanium alloys have become an indispensable structural material of advanced aircrafts, due to its high strength, good thermal stability, strong corrosion resistance and welding performance [1]. The globularization of titanium alloy with lamellar colony during hot working can obtain fine and homogeneous microstructure extensively used in aerospace field, which can ensure both optimal creep and optimal fatigue properties $[2,3]$. The inhomogenous globularization [4] often leads to the formation of microdefects (mixed grains, microstructure heredity and macrozone $[5,6])$ which seriously affect mechanical properties of aviation components. Therefore, precise control on globularization of titanium alloy with lamellar colony would exert a great significance for optimizing hot-working parameters, predicting and regulating microstructure and improving properties of titanium alloy products.

The shortcomings of the well-known globularization mechanisms make it difficult to control globularization during hot working. The mains are follows: (a) the applicable conditions of every globularization mechanism

\footnotetext{
* e-mail: lihongwei@nwpu.edu.cn
}

are inconsistent (dynamic recrystallization at high temperature and low strain rate [7], shearing mechanism [8] at low temperature and high strain rate); (b) the microstructure parameters considered in every globularization mechanism are different (dihedral angle of the boundary in boundary splitting $[9,10]$, solute concentration gradient in termination migration $[11,12]$ ); (c) multiple mechanism coexistence due to the diversity of lamellar colony and meso-scale heterogeneous deformation [13-16]. Therefore, a unified globularization mechanism of coupling multiple factors needs to be further developed.

The limit application of prediction models cannot effectively guide the control process of globularization of titanium alloy with lamellar colony. The advantages of every prediction models are different. The relationships between hot-working parameters and globularization fraction are predicted by empirical model $[17,18]$ and neural network model [19]. The processing map [20,21] can be used to determine the process parameter interval of steady globularization state without micro-defects. The internal variable model $[3,22]$ can precisely predict the evolution of globularization fraction, dislocation density and flow softening. Meanwhile, the phase field model $[23,24]$ can predict the morphology evolution of single alpha lamella during static globularization without 


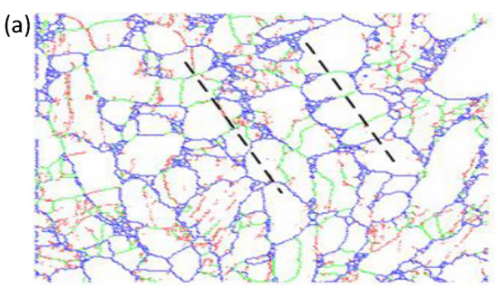

(b)

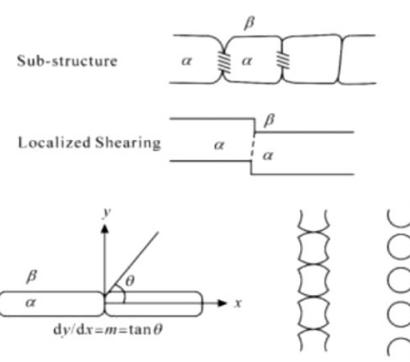

(c)

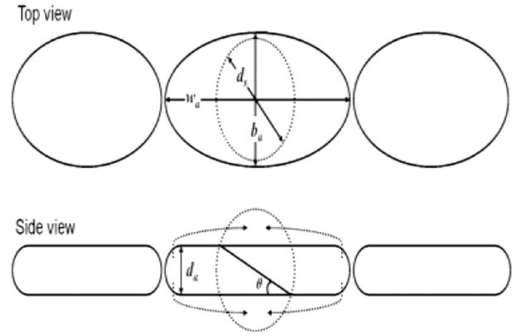

(d)

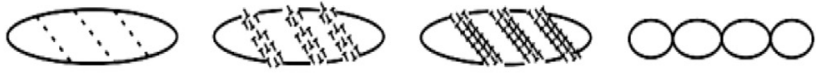

(e)
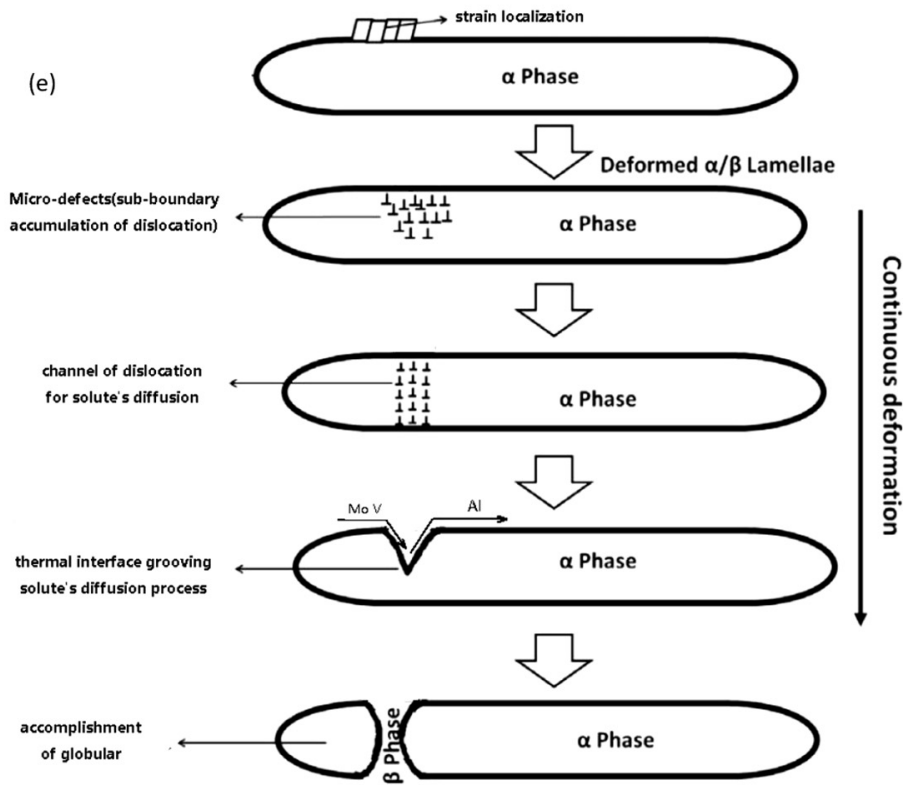

Fig. 1. globularization mechanisms: (a) dynamic recrystallization [7]; (b) boundary splitting [32]; (c) termination migration [33]; (d) shearing mechanism [34]; (e) unified globularization mechanism of coupling multiple factors.

consideration of hot deformation. The meso-scale heterogeneous deformation can be well captured by microstructure-based finite element model [13,16,25,26].

The hot deformation of titanium alloy in the (alpha + beta) phase field is a complex thermal mechanical process with coupling effects of multi-fields and multi-factors [27]. The thermal mechanical process is very sensitive to hotworking parameters and microstructure parameters, thus resulting in the difficulty in precisely controlling globularization. The detailed characteristics are described as follows: (a) complex and diverse morphologies (initial widmanstatten alpha [4], secondary alpha [28] and fine acicular martensitic alpha [29]) lead to the difference in globularization dynamics; (b) the meso-scale heterogeneous deformation (strain localization at lamellar-scale, strain partitioning behavior at colony-scale, macro-deformation bands at polycrystal-scale [15]); (c) the complex coupling effects of hot-working parameters and microstructure parameters (flow softening due to loss of interfacial coherency [3], evolution of geometry necessary dislocation(GND) at alpha/beta interface [29], the effect of lattice rotation $[14,30]$ on meso-scale heterogeneous deformation). In general, an in-depth understanding of the effects of hot-working parameters and microstructure parameters can allow better control globularization of titanium alloy with lamellar colony.

To deepen understanding and precisely controlling on globularization, this paper summarizes research on globularization, mainly including globularization mechanism, prediction models and the effects of hot-working parameters and microstructure parameters. Those puzzles and challenges ('sluggish' problem [31] and macrozone) faced by the control globularization process and the corresponding solutions are also put forward.

\section{State of art on globularization mechanism}

\subsection{Globularization mechanisms of lamellar colony \\ 2.1.1 Dynamic recrystallization}

Some researchers believed that the dynamic recrystallization was the major mechanism triggering the globularization in the (alpha+beta) phase region. The experiment of He et al. [7] found that lamellar colony was split into necklace strings with similar orientation, which was the major symbol of continuous dynamic recrystallization shown in Figure 1a. Lamellar colony was squashed to fractured short-bar alpha by large deformation, which is feature of geometric dynamic recrystallization [35].

Nonetheless, dynamic recrystallization and dynamic globularization cannot be equally viewed for following reasons. Firstly, the kinetics of dynamic recrystallization and globularization are similar but slightly different. The critical strain of dynamic globularization is larger than the strain corresponded by peak stress [36], which is shown in Figure 2. Secondly, dynamic recrystallization is an important flow softening mechanism, while the flow softening of titanium alloy during globularization is mainly caused by kinking, rotation and loss of Hall-Petch effect $[3,37]$ of lamellar colony. In addition, the sub-grain 


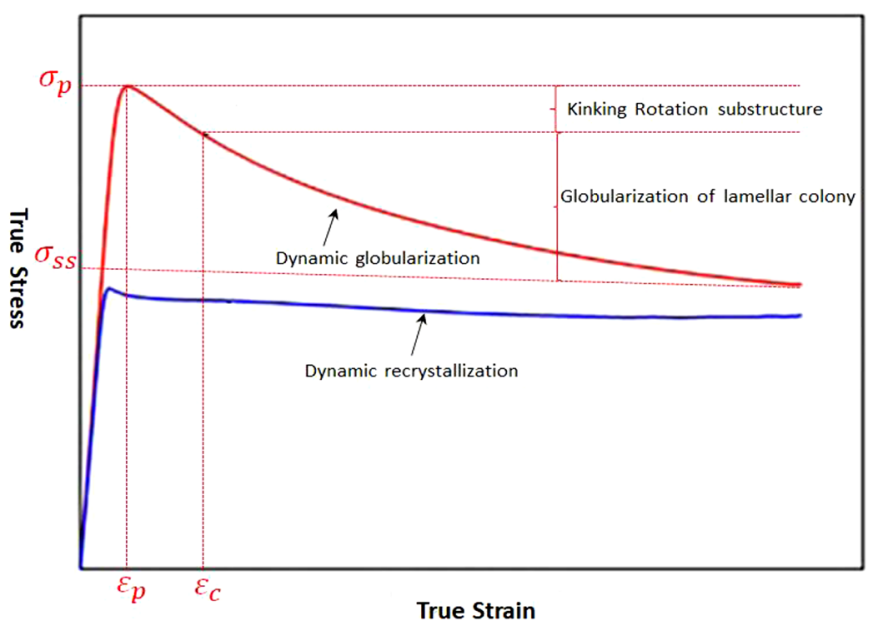

Fig. 2. The stain-stress curve of dynamic recrystallization and dynamic globularization [38].

boundary and the high-energy unstable interface formed in dynamic recrystallization are necessary preconditions for globularization.

\subsubsection{Boundary splitting}

Boundary splitting $[9,10]$ is generally accepted as a globularization mechanism of titanium alloy shown in Figure 1b. Sub-boundaries would form in the initial lamellar alpha or under the effect of shearing after certain deformation by cold/hot working. The subboundary's dihedral angle is of $90^{\circ}$ and unstable. In order to lessen interfacial tension, that dihedral angle would decrease gradually along with the wedging of beta phase into alpha/beta interface. Meanwhile, alpha/beta interface would reverse and lamellar structure would transform into globular structure, thus gaining globularization.

Nevertheless, boundary splitting does not consider the effects of dislocation density [39] and solute concentration gradient [40] on globularization. Since the globularization is thermal diffusion process and in agreement with the Fick's second diffusion law. Different solute concentration affects the migration kinetics of interface, thus influencing the wedging of beta phase. Moreover, the dislocation density accumulated at alpha/ beta interface offered channel and force for solute atom's diffusion.

\subsubsection{Shearing mechanism}

According to shearing mechanism shown in Figure 1d [8], under the effect of shear strain, the lamellar alpha colony with favorable orientation is conducive to shear deformation while the rotation is aroused in alpha phase with unfavorable orientation. Moreover, dislocations would gather along the shear line latter. Dynamic recovery leads to dislocations of opposite signs annihilating. Due to dislocations of same signs, interfaces generate along shear lines and migrate to minimize the surface energy, hence promoting the form of the globular alpha.
The limited applicable condition is apparent shortcoming of shearing mechanism. Under the condition of low temperature and high strain rate, the slower rate of atomic diffusion or inadequate diffusion time lead to the difficulty in globularization through interface migration for lamellar alpha with long axial ratio. Lamellar alpha with the low axial ratio can get globularization due to the strong shear fracture. Therefore, shearing can provide micro-defects and condition for interface migration of dynamic globularization.

\subsubsection{Termination migration}

Termination migration $[11,12]$ is an important static globularization mechanism shown in Figure 1c. The lamellar colony is taken into account as a whole. By contrast, single alpha lamella is considered in all those models described previously. The concentration gradient would exist and cause mutual atom diffusion in alpha lamella as driving force. Over time, some alpha lamellas get coarsened and others get shortened, thus gaining globularization. And this kind of termination migration would happen apparently at the termination of the lamellar alpha.

Although the termination migration can achieve the final globularization, it cannot be completely separated from the previous dynamic globularization. Because the lamellar colony of titanium alloy is very stable, it cannot be spheroidized by the cycle heat treatment as steel does. Only the alpha lamella with high-energy instability interface generated by the strong hot deformation can be spheroidized by the termination migration at high temperature.

\subsection{Shortcomings of globularization mechanism}

The research status and results of globularization mechanism described above indicates that the shortcomings of globularization mechanisms are apparent. Firstly, globularization mechanisms belong to qualitative descriptions [32], yet lacking quantitative characterization on microstructure parameters, such as dislocation density, crystal orientation and substructure etc. Secondly, those four globularization mechanisms mentioned above are only applicative to specific conditions of globularization behavior (dynamic recrystallization at high temperature and low strain rate, termination migration at heat treatment). Therefore, in light of the coexistence of multiple mechanisms, new globularization mechanism needs to be further developed.

\subsection{Unified globularization mechanism}

In light of the coexistence and advantages of multiple mechanisms, a new unified globularization mechanism of coupling multiple factors is pointed out on the work of Roy [41] shown in Figure 1e. The detailed features are described below: Firstly, the meso-scale deformation inhomogeneity in alpha and beta causes strain localization to emerge at phase interface, leading to the occurrence of micro-defects (unstable phase interface and sub-grain boundary with high energy) and dislocation density accumulated on phase 
interface. Secondly, with aggravation of deformation degree, due to the differences in solute concentration gradient, solute atom passes the dislocation channel and crosses interface, triggering the formation of thermal grooving. Thirdly, the diffusion rate and path of solute element is affected by curvature effect, solute atom's dragging effect [42] and solute concentration gradient. The alpha stable solute atom $\mathrm{Al}$ in the interface near the thermal grooving are concentrated and the concentration of beta stable solute atom Mo is lower. The concentration difference of the solute drives the opposite diffusion, leading to the gradual dissolution of the alpha phase near the thermal grooving, the deepening wedging of the beta phase.

\section{Status of prediction models on globularization}

\subsection{Limited applications of prediction models}

The development of modeling and simulation tools was very important and could provide guidance for microstructure and mechanical property optimization. The computerbased simulation tools could develop next-generation components and processes in the aerospace industry [43]. Based on the study of the globularization mechanism, many researchers have established the prediction models of globularization. These models are summarized as follows: empirical model [17,18], neural network model [19], internal variable model [3,22], processing map [20,21], phase field model $[23,24]$ and microstructure-based finite element model $[13,16,25,26]$. Moreover, the comparison and analysis of these prediction models are accomplished through tabular form shown in Table 1.

These models possess prominent advantages respectively. Based on globularization mechanism of dynamic recrystallization, empirical model and neural network model can describe the quantitative correlation of the hotworking parameters (temperature strain and strain rate) and microstructure evolution parameters (dynamic/static globularization volume fraction, initiation strain, completion strain, annealing completion time). To some extent, internal variable model, and phase field model could reflect the microstructure evolution and the complex physical mechanism of globularization during hot working. However, the shortcomings of these models lead to limited applications. Failing to consider the effects of hot-working parameters, the phase field model cannot effectively predict the rate of globularization, the initiation position of globularization and volume fraction on the basis of Termination migration. Nonetheless, these models do not have the capacity to couple microstructure parameters with hot-working parameters on globularization. It is impossible to precisely control the globularization of titanium alloy with lamellar colony and guide the production practice through theses prediction model.

\subsection{Multi-scale CACPFEM modeling of globularization}

Currently, studies on multi-scale model of globularization during hot working are scarce. A multi-scale model which combines crystal plasticity finite element with cellular automaton [44-47] could simulate microstructure evolution and meso-scale deformation under the effects of hotworking parameters and microstructure parameters. This provides a good idea and reference for the modeling of globularization.

Therefore, a framework scheme of multi-scale cellular automation and crystal plasticity finite element model (CACPFEM) on globularization was proposed shown in Figure 3. The microstructure-based crystal plasticity finite element model (CPFEM) includes the evolution of GND [48-53] in the alpha/beta interface, the reconstruction of high temperature beta phase [54-58] and three-dimensional reconstruction of alpha lamella $[59,60]$. Local variables such as dislocation density, deformation storage energy and grain orientation could be worked out. Then those local variables would be inputted into the cellular automation (CA) model, which considers the curvature effect of phase interface and solute concentration gradient to conduct morphological evolution of alpha lamella. Therefore, this multi-scale coupling model could not only gain meso-scale deformation such as stress and strain field, but also obtain micro-scale morphological distribution.

\section{Effect of hot working and microstructure}

The globularization of lamellar colony is affected by the coupling effects of hot-working parameters and microstructure parameters. However, there are few studies on the influence of micorstructure parameters on lamellar globularization, which basically remain in lath thickness [62], burger orientation [63], morphological effects on anisotropic deformation [16]. In this section, the effects of hot-working parameters (strain, strain rate, temperature) and microstructure parameters (alpha/beta interface $[64,65]$, GND, high-temperature beta phase $[2,66])$ on globularization are systematically summarized. Moreover, these puzzles and challenges('sluggish' problem [31] and macrozone) faced by the control globularization process are also pointed out, and some innovative solutions are proposed for these puzzles.

\subsection{Effect of hot working on globularization}

\subsubsection{Effect of strain}

Without the effect of strain, the globularization of lamellar colony cannot be accomplished only by heat treatment. From micro-perspective, the strain can promote the formation of micro-defects and the accumulation of distortion energy, destroy the stability of the alpha/beta interface and increase the probability of lamellar cutting. Moreover, the slip systems in the close-packed hexagonal structure alpha phase are limited and the critical resolved shear stress (CRSS) of each slip system is relatively large $[67,68]$. From the perspective of macroscopic deformation, strain also affects the kinetics of globularizaiton [69,70]. The globularization fraction increases with the increase of strain [71]. The initiation strain and completion strain of globularization increase with the thickness of the lamellar alpha. The impact of strain on globularization is also 


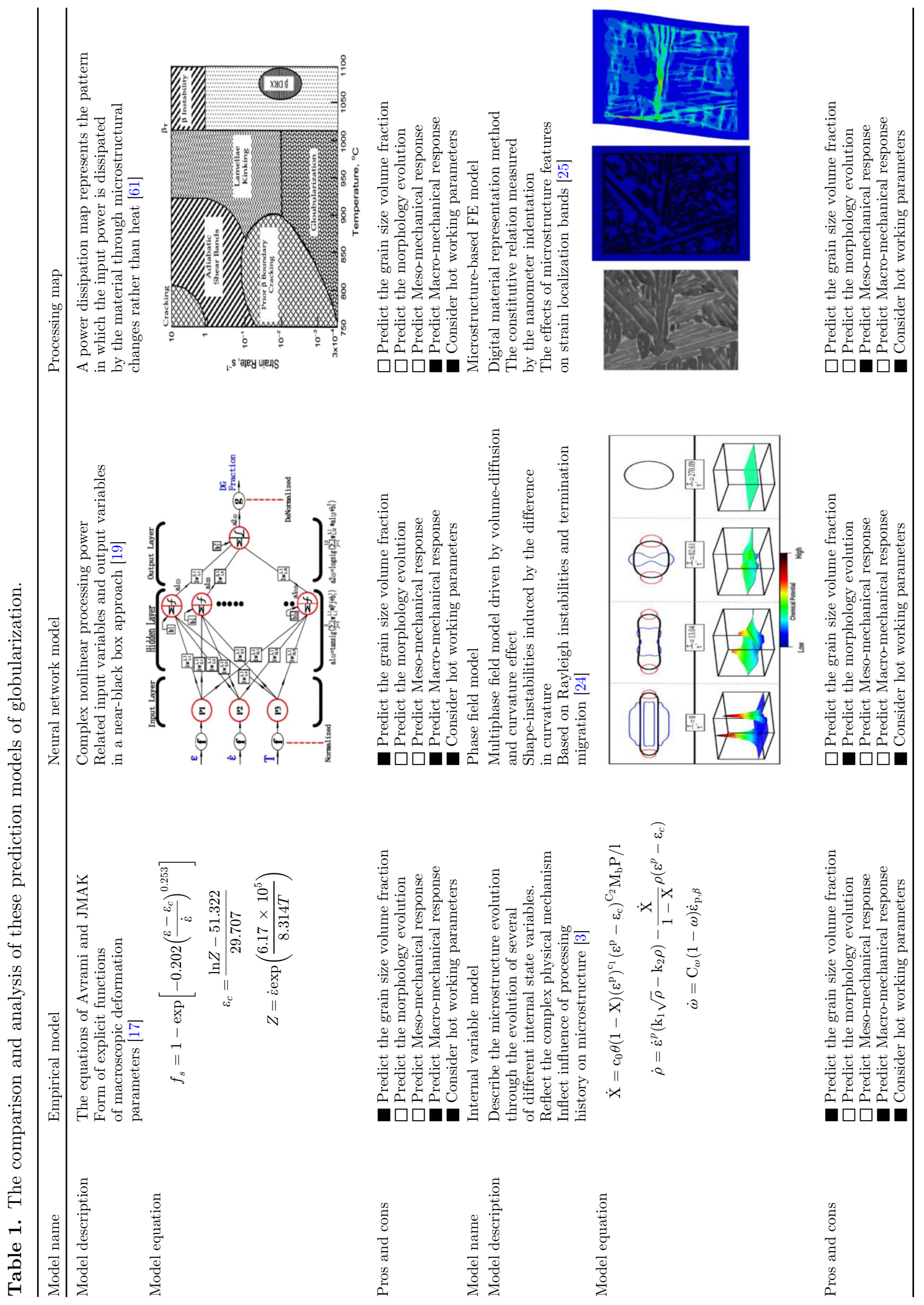




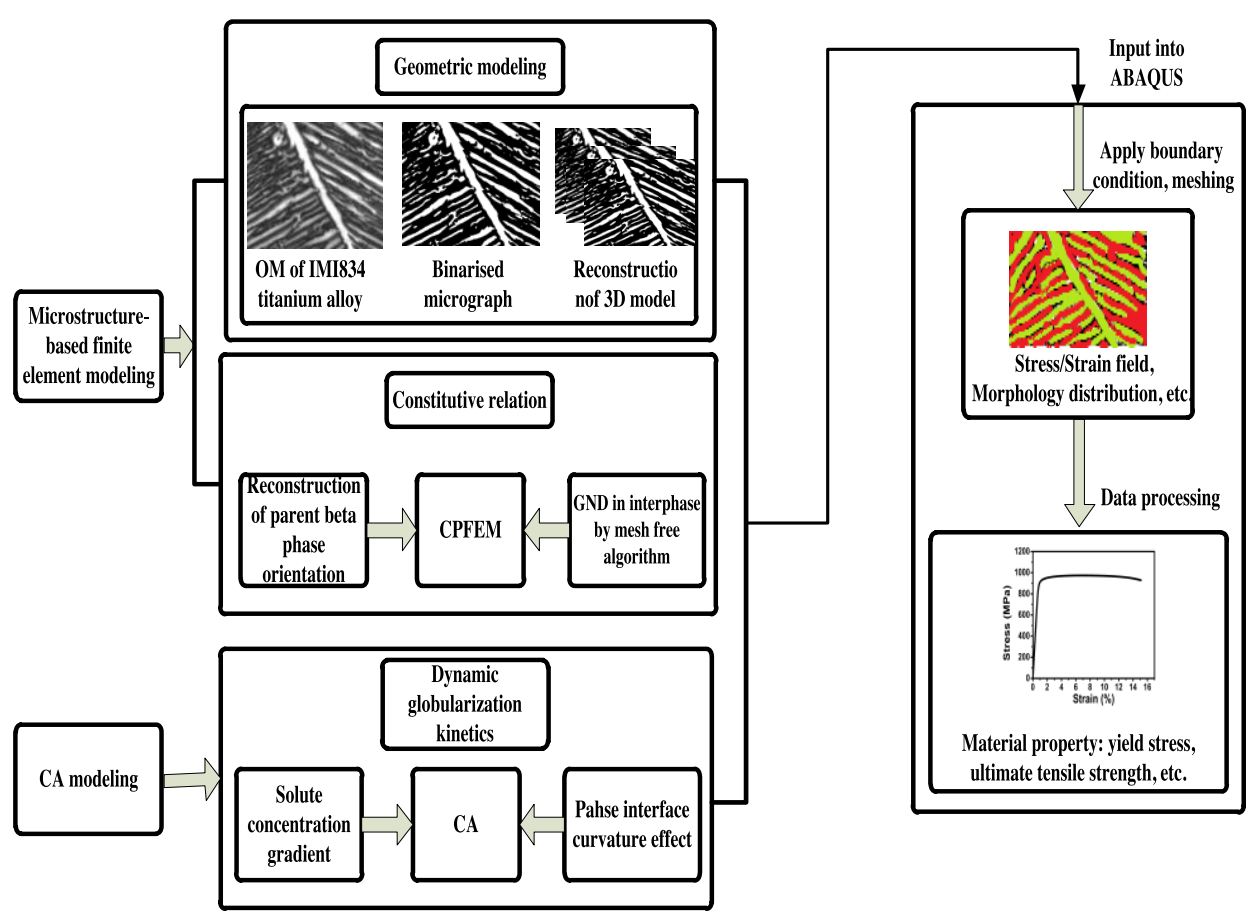

Fig. 3. Scheme of Multi-scale CACPFEM modeling of globularization.

related to the composition of the alloy. In the $(\alpha+\beta)$ working, the initiation strain and completion strain of globularization of near alpha titanium alloy are bigger than that of near beta titanium alloy. The work of $\mathrm{Wu}[72]$ and Wang [31] are well to verify this conclusion. Abundant beta stable solutes result in not only relatively small lamellar alpha, but also high solute diffusion rate.

\subsubsection{Effect of strain rate}

Strain rate has a significantly effect on globularization of titanium alloy with lamellar colony, especially on the rate of globularization. The high strain rate leads to meso-scale inhomogeneous plastic deformation (flow instability, strain localization and adiabatic shear band [73]). Although high strain rate can promote fracture and brings more micro-defects, inhibits interfacial migration, its globularization efficiency is not high. The interfacial migration will be more complete at low strain rate which could accelerate the wedging of beta phase and cause fracture of single alpha lamella due to the faster diffusion rate and sufficient diffusion time. Therefore, high temperature and low strain rate are applicable hotworking parameters for globularization during hot working. The globularization mechanism is also different with different strain rates. Some study showed that high strain rate easily caused shearing of alpha lamella, and the dynamic recrystallization was usual the globularization mechanism at low strain rate.

\subsubsection{Effect of temperature}

The effect of temperature on globularization is complex. The detailed characteristics are descriebd as follows: (a) Temperature affects not only the deformation inhomogeneity, but also the interface diffusion rate; (b) The temperature also has a great influence on complex and diverse morphologies of lamellar colony (the thickness, volume fraction and the kinetics of globularization). In detail, fine lamella such as martensite becomes thicker with the increase of temperature in the two phase region [74], while coarse lamella generated by the furnace cooling microstructure changes in an opposite way; (c) The temperature may also affect globularization mechanism. The globularization mechanism at high temperature was the dynamic recrystallization, while at low temperature was always the boundary splitting; (d) The effect of temperature not only embodies during the hot deformation process but also in the subsequent heat treatment process. The lamellar alpha structure transforms into short-bar shape or band-like shape after deformation in the two phases region and alpha grains with these shapes further get split or globular via annealing treatment.

\subsection{Effect of microstructure on globularization}

\subsubsection{Effect of alpha/beta interface}

This burger orientation (OR) [63,64] of titanium alloy with colony shown in Figure 4a provides the basis for the formation of coherent or semi-coherent interphase boundaries which have been verified by high-resolution transmission electron microscopy (TEM) [64]. At present, the research is focused on the influence of the lose coherency shown in Figure 4b on the flow softening. In fact, interfacial coherency is accompanied by the loss of Hall-Petch strengthening, which exhibit strong flow softening [3]. 


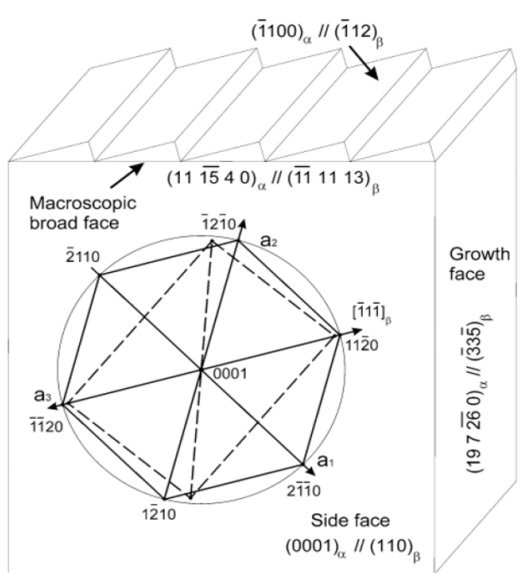

(a)

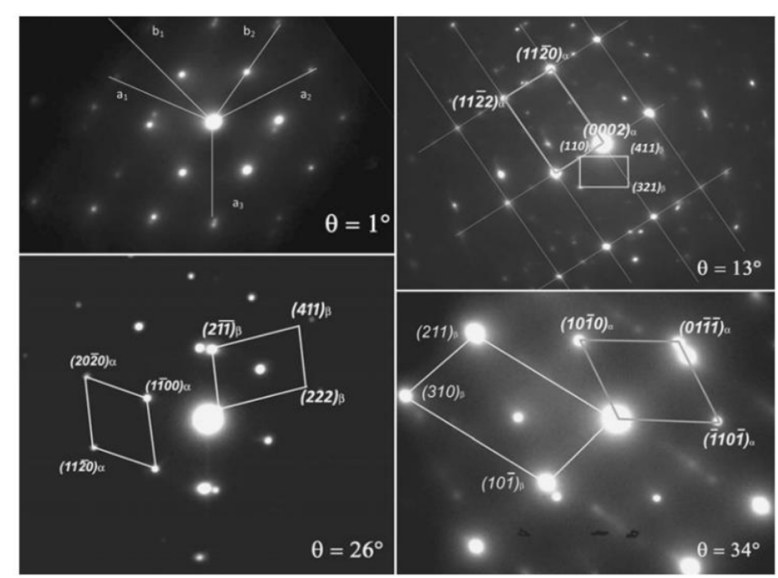

(b)

Fig. 4. (a) The crystallography relationship between the alpha and beta phases in Ti alloys. (b) alpha/beta interface deviation angles by TEM.
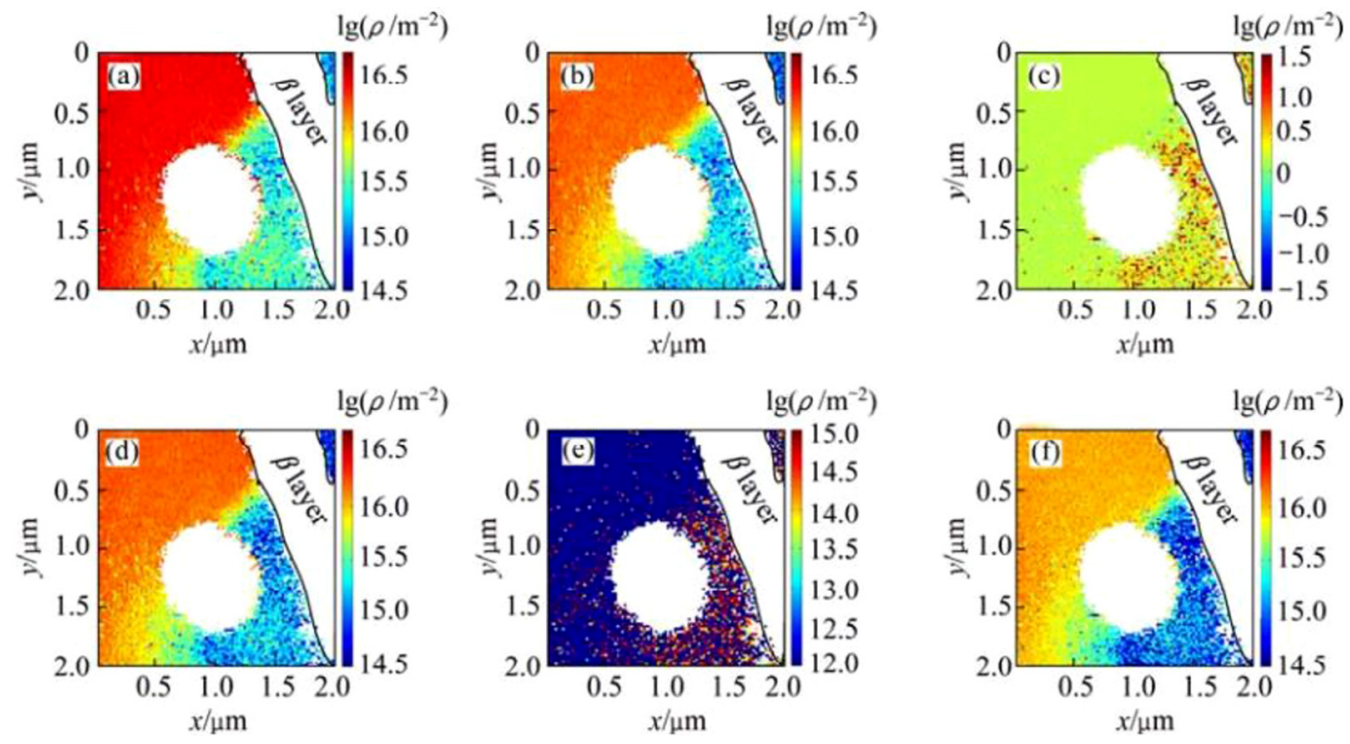

Fig. 5. HCP deconstructions of the GND density around indent [76]: (a) Total GND density. (b) type GND density. (c) Ratio of to $<\mathrm{c}+\mathrm{a}>$. (d) Basal-GND density. (e) Prismatic-GND density. (f) Pyramidal-GND density.

The lose coherency of alpha/beta interface becomes the hindrance of dislocation slipping and the interface energy could provide driving force for the formation of microdefects in the globularization process. However, the effect of the alpha/beta interface on the diffusion of solute atom during globularization is scarce. The diffusion of the solute atoms especially the Mo and V atoms are affected by the solute concentration gradient [33,40], solute atom's dragging effect [42] on the interface migration and the lose coherency of alpha/beta interface. Although literature [75] suggested the loss of coherency increased the rate of diffusion along the interphase boundaries resulting in an acceleration of the rate of globularization of the two phases, specific experimental research and quantitative analysis are needed. In addition, the effect of curvature on the phase interface could cause the difference of the diffusion driving force of the solute concentration, thus affecting the dynamics and morphology of the beta wedging.

\subsubsection{Effect of geometry necessary dislocation}

The study of Hiroaki [29] found that the GND was reduced after globularization, whereas still high in lamellar alpha. The evolution of the GND on interface has an effect on the formation of micro-defects and the thermal diffusion of solute. Moreover, the effect of GND [14,30] on meso-scale heterogeneous deformation of lamellar colony is very important. It is necessary to study the effect of GND on globularization of lamellar colony.

At present, the experimental research on GND in alpha/beta interface is still limited to small strain and local grain size. According to the research of $\mathrm{He}$ [76], GND in alpha/beta interface was high. However, the deformation distortion of beta phase was serious, which resulted in the calculation of GND of beta phase was difficult shown in Figure 5. Therefore, the value of stress/strain calculated by cross-correlation in the grain is relative value relative to the 

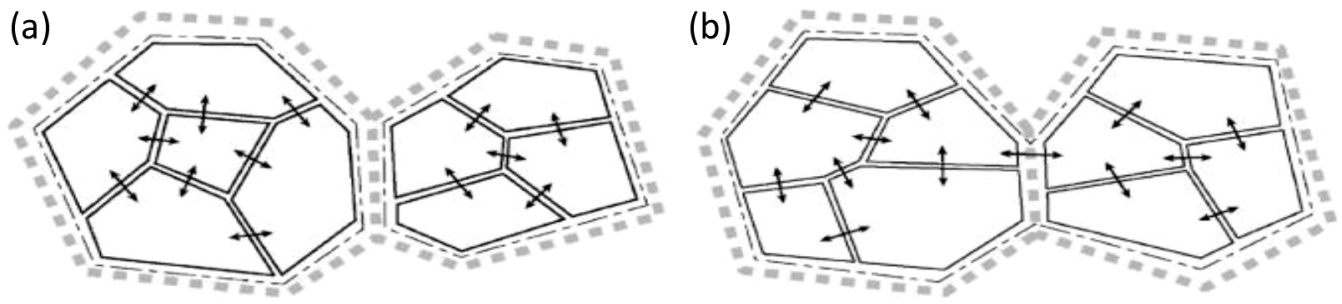

(c)

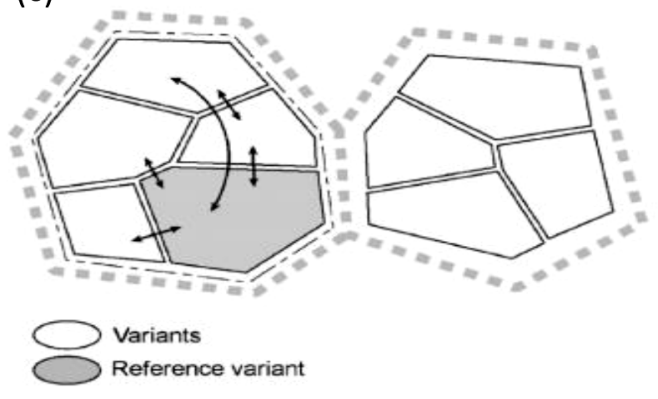

(d)

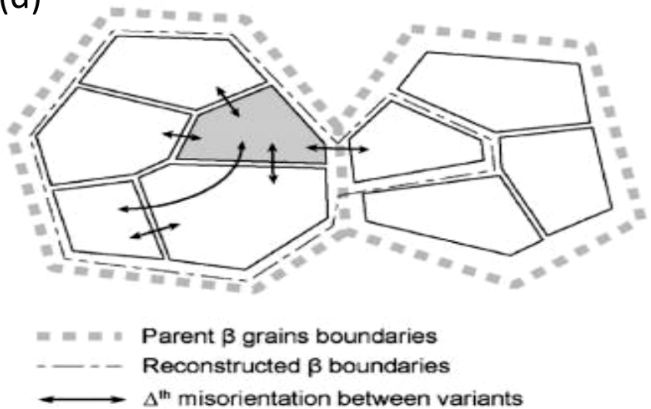

Fig. 6. Different strategies to gather the variants using a misorientation criterion-illustration on different situations of parent beta grains and inherited alpha variants [54].

reference point [77-79]. This means that the absolute value of the stress/strain cannot be calculated. The comparison between different grains has no practical significance. Quantitative determination of full-field GND at large strain is currently not available.

In addition to the experimental method, the simulation modeling analysis is also an important research method, thus shedding new light on solution of measurement problems on the full-field GND under large strain. An effective strategy is that the evolution law of GND on the small strain was quantitative characterized through the experiment measurement described above, and the finite element simulation model was proposed to study evolution of GND on large strain, thus studying the effect of GND on globularization. Due to the nonlocal characteristic of GND $[50,80,81]$, the numerical implementation of GND into the FEM framework would raise a number of fundamental problems. The specific research work can refer to the literatures $[51,52,82]$.

\subsubsection{Effect of high-temperature parent beta phase}

As well known to all, the beta phase plays an important role in the deformation compatibility between alpha lamella at high temperature. Moreover, beta phase is soft phase, experiencing severe plastic deformation. Beta phase also plays an important role in promoting wedging and solute atom's thermal diffusion in the globularization process. Studies on the effects of beta phase on the globularization during hot working are limited. In Germain's study [5], local characterization of the beta phase orientation from the lamellar colonies was hard to be obtained by existing measurement techniques. The reason is the lattice distortion caused by beta phase and low content of residual beta caused by phase transformation. These brought difficulty in the characterization of beta phase orientation through Electron Back-Scattered Diffraction (EBSD) measurement.
How to reconstruct beta phase orientation is the key to deeply study the effect of beta phase on globularization of lamellar colony. The difficulty in the reconstruction of high temperature beta parent phase rely on the determination from 12 possible beta parent phase [54-57] and the strategy of gathering the variants using a misorientation criterion [54]. According to the characteristic of alpha phase precipitation and burgers orientation relation, 12 possible alpha variants can randomly form from parent beta phase. The strategy to gather the variant from the same parent is also very important in the process of high temperature beta reconstruction, as shown in Figure 6. The specific details can refer to the literatures [54-57]. Moreover, the lattice distortion of beta phase get weakened through light corrosion and elimination of residual stress in the experimental process and the calibration rate of beta phase and secondary alpha phase get enhanced on EBSD. Therefore, the effect of beta phase on the globularization of alpha lamella can be studied by means of the hightemperature beta orientation reconstruction described above.

\subsection{Puzzles and challenges faced by globularization control}

4.3.1 Unified control strategy of hot deformation and heat treatment

The 'sluggish' problem of globularization of lamellar colony is that the globularization efficiency during hot working is low [31]. What's regrettable is that most of the techniques (changing loading paths [83] and beta pre-deformation [84]) to improve the globularization rate are not yet well accepted in the industrial domain due to high cost and low efficiency. The evolution of alpha lamella including the morphology of precipitation for phase transformation, globularization for hot deformation and termination migration for heat treatment, and the interact relationship between these are very complicated and sensitive. At 


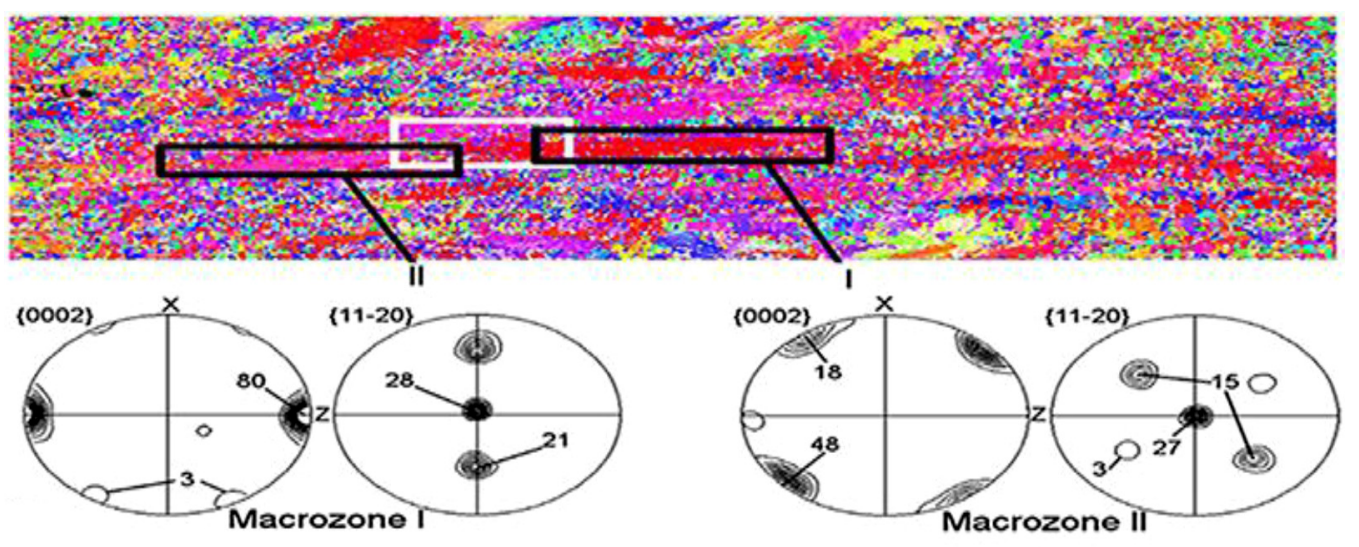

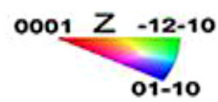

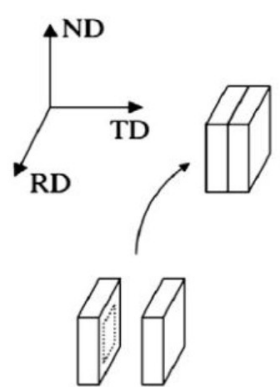

(b) $\underset{c D}{\oint_{C D}} x$

(a)

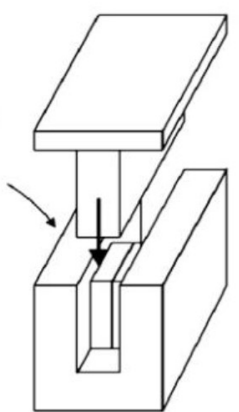

b)
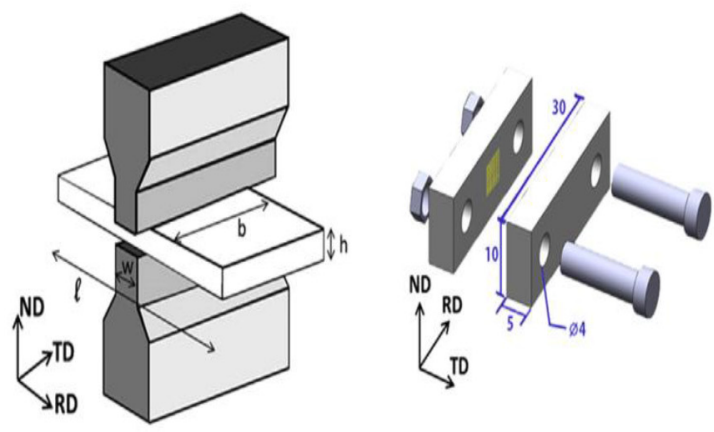

(c)

Fig. 7. (a) Macrozone [5]. (b) Schematic of the split sample and channel-die configuration [88]. (c) Plane strain compression test geometry and specimen geometry [91].

present, the study on the effects of combining hot deformation and heat treatment processing parameters are not much. The joint control strategy of hot deformation and heat treatment is used limitedly on the process of globularization on cogging and forging of billets and manufacturing of double performance disk.

Precise control of multi-process parameters of the whole process with coupling effects of multi-fields and multifactors is core of unified control strategy of hot deformation and heat treatment [1,27]. This kind of strategy is employed by Stefansson et al. [40] and the conclusion is that pre-imposed strain of hot deformation and annealing temperature made great effect on the globularization efficiency. Moreover, the globularization efficiency is improved by the interrupted multi-pass compression with inter-pass heat treatment in the work of Fan et al. [85]. As a consequence, precise control of the whole process with an appropriate process parameter is a promising strategy for microstructure control.

\subsubsection{Quantitative relation of the globularization and macrozone}

Inhomogeneous globularzaiton of initial coarse lamellar colony could easily lead to microstructure heredity. Relevant literatures $[5,6]$ indicated that many globular alpha grains still remain similar orientation, resulting in macroscopic defects with size up to $\mathrm{mm}$ which is called macrozone shown in Figure 7a. The macrozone has been observed in semi-fihished products such as billets as well as forged disks. The macrozone can act as sites of multiple initiating cracks and reduce the fatigue performances.

At present, researches into effects on macrozone from microstructure parameters including lamellar colony's initial morphology, distribution and orientation are insufficient especially the evolution of the local microtexture during globularization. Therefore, the quantitative relation of the globularization and macrozone is unclear. In the research of Germain [5], The compression test performed in this study cannot track in a fully accurate manner on the thermomechanical history of macrozone. Traditional deformation experiments involving uniaxial compression, tension or simple torsion are not suitable for in situ measurement of micro-texture heterogeneity at high temperature and large strain. During hot working, interrtupted in situ measurement method shown in Figure 7b-c put forward by Quey [86-88], Dancette [89] and Martin [90] can track the evolution history of microstructure parameters, such as microstructure morphology, distribution and orientation. The studies in initial morphology, distribution and orientation of lamellar colony and micro-texture evolution during the hot working 


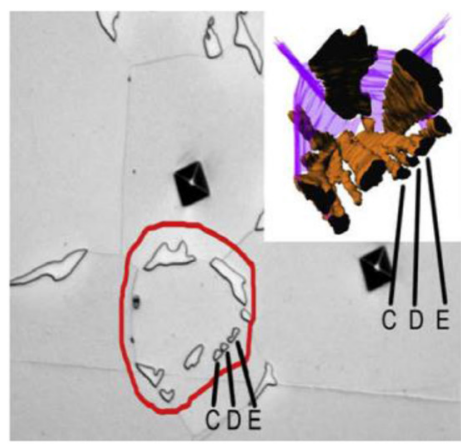

(a)

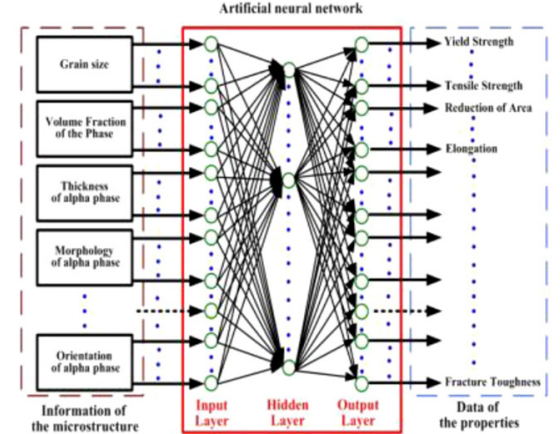

(b)

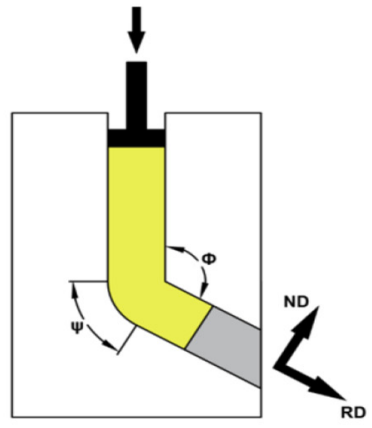

(c)

Fig. 8. (a) 3D construction of alpha lamella through multiple grinding and polishing [92]. (b) Artificial neural model of mechanical properties through the microstructure information [97]. (c) Equal-channel angular pressing [101].

would be of great significance for deepening understanding in formation mechanisms of macrozone and the relation of the globularization and macrozone.

\section{Development tendency of globularization}

\subsection{Microstructure evolution of three-dimensional lamellar colony}

With the development of analytical testing equipment and computer programming algorithm, the three-dimensional test characterization method of microstructure improves remarkably as well. As for three-dimensional reconstruction of titanium alloy lamellar colony, three main methods probably used are as follows: multiple levels of grinding and polishing technology [92] shown in Figure 8 (a), using three dimensional $\mathrm{X}$ rays diffraction $[93,94]$ and combining focused ion beam (FIB) with EBSD $[95,96]$. Up to now, studies taking advantage of FIB-EBSD on morphology and orientation of lamellar colony after globularization have not been reported yet. These factors such as morphology features of single alpha lamella, distribution relationships of alpha variants, three-dimensional interweave distribution characteristics and deformation compatibility of alpha colonies, would render a remarkable significance for deepening our understanding in lamellar colony's deformation mechanism, globularization laws and its mechanical and service performance as well.

\subsection{The relationship between lamellar colony and mechanical properties}

The quantitative research in microstructure and properties of titanium alloy during hot working renders an important foundation for optimizing design of titanium alloy microstructure. It is of great significance not only for effectively adjusting and controlling components' microstructure and properties but also for optimizing hotworking parameters. As for titanium alloy with lamellar colony, the effects of the average quantitative indexes (grain size, thickness and fraction of alpha) on mechanical properties of titanium alloy could be predicted in terms of the artificial neural model [97] shown in Figure 8b. But the effects of microstructure morphology, distribution or micro-texture on mechanical properties were scarce. Therefore, a computer-based simulation model [98] needs to be developed to study the quantitative relationship between microstructure parameters and mechanical properties.

\subsection{The effect of severe plastic deformation on globularization}

Severe plastic deformation (SPD) $[99,100]$ technique means that the material undergoes very large strain, which results in abnormal refinement of grain, but with unchanged geometry size of billets. The free flow of material is limited by the special mold shape in equalchannel angular pressing (ECAP) [101] shown in Figure 8c. The hydrostatic pressure can results in higher strain and high-density micro-defects. After several extrusions, the grain size can be refined after large plastic deformation. Shear deformation can promote microstructure fracture and globularizaiton of titanium alloy. The characteristics of unchanged shape and size are very suitable for cogging and forging of billets and pre-blocking of forged disk. The technique of ECAP can effectively increase the globularization efficiency of lamellar colony. Therefore, SPD may be a promising solution to 'sluggish' problem of globularizaiton. But the research on this is scarce. The application of ECAP techniques may be accepted and adopted in precisely controlling globularization by the engineering field.

\section{Conclusions}

This paper summarized the research work of globularization of lamellar colony, which mainly includes the globularization mechanisms, the prediction models and the effects of hot-working parameters and microstructure parameters. Some results are presented in the following section. 
- In light of the coexistence and advantages of multiple mechanisms, a unified globularization mechanism of coupling multiple factors is summarized.

- As for the prediction model, a framework scheme of multi-scale CACPFEM modeling on globularization is also introduced. Moreover, the coupled effects between micro-scale microstructure evolution and meso-scale deformation anisotropy can be well captured by this multi-scale CACPFEM.

- A unified control strategy of hot deformation and heat treatment is pointed out for the 'sluggish' problem of globularization during hot working. As for the formation of macrozone, an interrupted in-situ measurement method could be used to characterize the micro-texture evolution of globularization.

Consequently, these results described above is of great significance to in-depth understanding of globularization mechanism, predict and precise control on globularization and optimize the hot-working parameters and improve properties of titanium alloy products.

Acknowledgement. The author would like to thank the National Science Foundation of China (51675433) and the Natural Science Foundation for Distinguished Young Scholars of Shaanxi Province (2019JC-09).

\section{References}

1. L. Guo, X. Fan, G. Yu, H. Yang, Microstructure control techniques in primary hot working of titanium alloy bars: a review, Chin. J. Aeronaut. 29 (2016) 30-40

2. L. Li, M.Q. Li, J. Luo, Mechanism in the $\beta$ phase evolution during hot deformation of Ti-5Al-2Sn-2Zr-4Mo-4Cr with a transformed microstructure, Acta Mater. 94 (2015) 36-45

3. P. Gao, H. Yang, X. Fan, S. Zhu, Unified modeling of flow softening and globularization for hot working of two-phase titanium alloy with a lamellar colony microstructure, J. Alloys Comp. 600 (2014) 78-83

4. S.C.V. Lim, K.V. Yang, Y. Yang, Y. Cheng, A. Huang, X. $\mathrm{Wu}$, C.H.J. Davies, Tracking microstructure, texture and boundary misorientation evolution of hot deformed and post-deformation annealed Ti-6Al-4V alloy, Mater. Sci. Eng. A 651 (2016) 524-534

5. L. Germain, N. Gey, M. Humbert, P. Vo, M. Jahazi, P. Bocher, Texture heterogeneities induced by subtransus processing of near $\alpha$ titanium alloys, Acta Mater. 56 (2008) 4298-4308

6. N. Gey, P. Bocher, E. Uta, L. Germain, M. Humbert, Texture and microtexture variations in a near- $\alpha$ titanium forged disk of bimodal microstructure, Acta Mater. 60 (2012) 2647-2655

7. D. He, J.C. Zhu, Z.H. Lai, Y. Liu, X.W. Yang, An experimental study of deformation mechanism and microstructure evolution during hot deformation of Ti-6Al-2Zr1Mo-1V alloy, Mater. Des. 46 (2013) 38-48

8. T. Seshacharyulu, S. Medeiros, J. Morgan, J. Malas, W. Frazier, Y. Prasad, Hot deformation mechanisms in ELI Grade Ti-6a1-4V-A compendium of processing maps, Scr. Mater. 41 (1999) 283-288

9. H. Margolin, P. Cohen, Evolution of the Equiaxed Morphology of Phases in Ti- 6 Al- 4V, Titanium'80 1 (1980) 1555-1561
10. I. Weiss, G. Welsch, F. Froes, D. Eylon, Mechanisms of microstructure refinement in Ti-6 Al-4 V alloy, Titanium Sci. Technol. (1985) 1503-1510

11. N. Stefansson, S. Semiatin, Mechanisms of globularization of Ti-6Al-4V during static heat treatment, Metal. Mater. Trans. A 34 (2003) 691-698

12. N. Stefansson, S. Semiatin, D. Eylon, The kinetics of static globularization of Ti-6Al-4V, Metal. Mater. Trans. A 33 (2002) 3527-3534

13. L. Chen, T.E. James Edwards, F. Di Gioacchino, W.J. Clegg, F.P.E. Dunne, M.-S. Pham, Crystal plasticity analysis of deformation anisotropy of lamellar TiAl alloy: 3D microstructure-based modelling and in-situ microcompression, Int. J. Plasticity 119 (2019) 344-360.

14. F.P.E. Dunne, R. Kiwanuka, A.J. Wilkinson, Crystal plasticity analysis of micro-deformation, lattice rotation and geometrically necessary dislocation density, Proc. Roy. Soc. A 468 (2012) 2509-2531

15. T.E.J. Edwards, F. Di Gioacchino, W.J. Clegg, An experimental study of the polycrystalline plasticity of lamellar titanium aluminide, Int. J. Plasticity 118 (2019) 291-319

16. X.G. Fan, X.Q. Jiang, X. Zeng, Y.G. Shi, P.F. Gao, M. Zhan, Modeling the anisotropy of hot plastic deformation of twophase titanium alloys with a colony microstructure, Int. J. Plasticity 104 (2018) 173-195

17. X.-j. Dong, S.-q. Lu, H.-z. Zheng, Dynamic spheroidization kinetics behavior of Ti-6. 5Al-2Zr-1Mo-1V alloy with lamellar microstructure, Trans. Nonferrous Metals Soc. China 26 (2016) 1301-1309

18. X.G. Fan, H. Yang, S.L. Yan, P.F. Gao, J.H. Zhou, Mechanism and kinetics of static globularization in TA15 titanium alloy with transformed structure, J. Alloys Comp. 533 (2012) 1-8

19. K.-x. Wang, W.-d. Zeng, Y.-q. Zhao, Y.-t. Shao, Y.-g. Zhou, Prediction of dynamic globularization of Ti-17 titanium alloy with initial lamellar microstructure during hot compression, Mater. Sci. Eng. A 527 (2010) 6193-6199

20. A.B. Li, L.J. Huang, Q.Y. Meng, L. Geng, X.P. Cui, Hot working of Ti-6Al-3Mo-2Zr-0. 3Si alloy with lamellar $\alpha+\beta$ starting structure using processing map, Mater. Des. 30 (2009) 1625-1631

21. S.-q. Lu, X. Li, K.-l. Wang, X.-j. Dong, M.W. Fu, High temperature deformation behavior and optimization of hot compression process parameters in TC11 titanium alloy with coarse lamellar original microstructure, Trans. Nonferrous Metals Soc. China 23 (2013) 353-360

22. Q. Bai, J. Lin, T.A. Dean, D.S. Balint, T. Gao, Z. Zhang, Modelling of dominant softening mechanisms for Ti-6Al-4V in steady state hot forming conditions, Mater. Sci. Eng. A 559 (2013) 352-358

23. P.G. Kubendran Amos, L.T. Mushongera, B. Nestler, Phase-field analysis of volume-diffusion controlled shapeinstabilities in metallic systems-I: 2-Dimensional plate-like structures, Comput. Mater. Sci. 144 (2018) 363-373

24. P.G. Kubendran Amos, E. Schoof, D. Schneider, B. Nestler, On the globularization of the shapes associated with alphaprecipitate of two phase titanium alloys: Insights from phase-field simulations, Acta Mater. 159 (2018) 51-64

25. K. Muszka, L. Madej, B.P. Wynne, Application of the digital material representation to strain localization prediction in the two phase titanium alloys for aerospace applications, Arch. Civil Mech. Eng. 16 (2016) 224-234 
26. D. Deka, D.S. Joseph, S. Ghosh, M.J. Mills, Crystal plasticity modeling of deformation and creep in polycrystalline Ti-6242, Metal. Mater. Trans. A 37 (2006) 1371-1388

27. P.F. Gao, H. Yang, X.G. Fan, Quantitative analysis of the microstructure of transitional region under multi-heat isothermal local loading forming of TA15 titanium alloy, Mater. Des. 32 (2011) 2012-2020

28. K. Wang, M.Q. Li, Morphology and crystallographic orientation of the secondary $\alpha$ phase in a compressed $\alpha / \beta$ titanium alloy, Scr. Mater. 68 (2013) 964-967

29. H. Matsumoto, T. Nishihara, Y. Iwagaki, T. Shiraishi, Y. Ono, A. Chiba, Microstructural evolution and deformation mode under high-temperature-tensile-deformation of the Ti-6Al-4V alloy with the metastable $\alpha /$ martensite starting microstructure, Mater. Sci. Eng. A 661 (2016) $68-78$

30. Z. Zhang, D. Lunt, H. Abdolvand, A.J. Wilkinson, M. Preuss, F.P.E. Dunne, Quantitative investigation of micro slip and localization in polycrystalline materials under uniaxial tension, Int. J. Plasticity 108 (2018) 88-106

31. K. Wang, W. Zeng, Y. Zhao, Y. Lai, Y. Zhou, Dynamic globularization kinetics during hot working of Ti-17 alloy with initial lamellar microstructure, Mater. Sci. Eng. A $\mathbf{5 2 7}$ (2010) 2559-2566

32. J. Fang, K.-l. Wang, S.-q. Lu, X.-f. Lu, Progress on globularization mechanisms and models in titanium alloys with lamellar structure, Mater. Res. Appl. 1 (2010)

33. C.H. Park, J.W. Won, J.-W. Park, S.L. Semiatin, C.S. Lee, Mechanisms and kinetics of static spheroidization of hot-worked Ti-6Al-2Sn-4Zr-2Mo-0. 1Si with a lamellar microstructure, Metal. Mater. Trans. A 43 (2011) 977-985

34. F. Pilehva, A. Zarei-Hanzaki, S. Moemeni, A.R. Khalesian, High-temperature deformation behavior of a Ti-6Al-7Nb alloy in dual-phase $(\alpha+\beta)$ and single-phase $(\beta)$ regions, J. Mater. Eng. Perform. 25 (2015) 46-58

35. L.R. Wang, Y.Q. Zhao, L. Zhou, Effect of hot rolling on the structure of TC21 alloy with acicular alpha, Mater. Manufactur. Processes 27 (2012) 154-159

36. K. Wang, W. Zeng, Y. Zhao, Y. Lai, X. Zhang, Y. Zhou, Flow behaviour and microstructural evolution of Ti-17 alloy with lamellar microstructure during hot deformation in $\alpha+$ $\beta$ phase field, Mater. Sci. Technol. 27 (2011) 21-28

37. X. Fan, H. Yang, P. Gao, Prediction of constitutive behavior and microstructure evolution in hot deformation of TA15 titanium alloy, Mater. Des. 51 (2013) 34-42

38. P. Gao, M. Fu, M. Zhan, Z. Lei, Y. Li, Deformation behavior and microstructure evolution of titanium alloys with lamellar microstructure in hot working process: a review, J. Mater. Sci. Technol. 39 (2020) 56-73

39. B. Babu, L.-E. Lindgren, Dislocation density based model for plastic deformation and globularization of Ti-6Al-4V, Int. J. Plasticity 50 (2013) 94-108

40. S. Zherebtsov, M. Murzinova, G. Salishchev, S.L. Semiatin, Spheroidization of the lamellar microstructure in Ti-6Al-4V alloy during warm deformation and annealing, Acta Mater. 59 (2011) 4138-4150

41. S. Roy, S. Suwas, The influence of temperature and strain rate on the deformation response and microstructural evolution during hot compression of a titanium alloy Ti6Al-4V-0.1B, J. Alloys Comp. 548 (2013) 110-125
42. C. Wu, H. Yang, H. Li, X. Fan, Static coarsening of titanium alloys in single field by cellular automaton model considering solute drag and anisotropic mobility of grain boundaries, Chin. Sci. Bull. 57 (2012) 1473-1482

43. M.G. Glavicic, V. Venkatesh, Integrated computational materials engineering of titanium: current capabilities being developed under the metals affordability initiative, Jom 66 (2014) 1310-1320

44. W. Chuan, Y. He, L.H. Wei, Modeling of discontinuous dynamic recrystallization of a near- $\alpha$ titanium alloy IMI834 during isothermal hot compression by combining a cellular automaton model with a crystal plasticity finite element method, Comput. Mater. Sci. 79 (2013) 944-959

45. H. Li, X. Sun, H. Yang, A three-dimensional cellular automata-crystal plasticity finite element model for predicting the multiscale interaction among heterogeneous deformation, DRX microstructural evolution and mechanical responses in titanium alloys, Int. J. Plasticity 87 (2016) $154-180$

46. H. Li, C. Wu, H. Yang, Crystal plasticity modeling of the dynamic recrystallization of two-phase titanium alloys during isothermal processing, Int. J. Plasticity 51 (2013) 271-291

47. E. Popova, Y. Staraselski, A. Brahme, R.K. Mishra, K. Inal, Coupled crystal plasticity - Probabilistic cellular automata approach to model dynamic recrystallization in magnesium alloys, Int. J. Plasticity 66 (2015) 85-102

48. M.F. Ashby, The deformation of plastically non-homogeneous materials, Philos. Mag. 21 (1970) 399-424

49. P. Cermelli, M.E. Gurtin, On the characterization of geometrically necessary dislocations in finite plasticity, J. Mech. Phys. Solids 49 (2001) 1539-1568

50. A. Ma, F. Roters, D. Raabe, A dislocation density based constitutive model for crystal plasticity FEM including geometrically necessary dislocations, Acta Mater. 54 (2006) 2169-2179

51. T. Takaki, Y. Tomita, Static recrystallization simulations starting from predicted deformation microstructure by coupling multi-phase-field method and finite element method based on crystal plasticity, Int. J. Mech. Sci. 52 (2010) 320-328

52. H. Zhang, X. Dong, Physically based crystal plasticity FEM including geometrically necessary dislocations: numerical implementation and applications in micro-forming, Comput. Mater. Sci. 110 (2015) 308-320

53. H.-m. Zhang, X.-h. Dong, Q. Wang, H.-z. Li, Micro-bending of metallic crystalline foils by non-local dislocation density based crystal plasticity finite element model, Trans. Nonferrous Metals Soc. China 23 (2013) 3362-3371

54. L. Germain, N. Gey, M. Humbert, Reliability of reconstructed $\beta$-orientation maps in titanium alloys, Ultramicroscopy 107 (2007) 1129-1135

55. M. Glavicic, P. Kobryn, T. Bieler, S. Semiatin, An automated method to determine the orientation of the high-temperature beta phase from measured EBSD data for the low-temperature alpha-phase in Ti-6Al-4V, Mater. Sci. Eng. A 351 (2003) 258-264

56. M. Humbert, F. Wagner, C. Esling, Numbering the crystallographic variants in phase transformation, J. Appl. Crystall. 25 (1992) 724-730 
57. M. Humbert, F. Wagner, H. Moustahfid, C. Esling, Determination of the orientation of a parent $\beta$ grain from the orientations of the inherited $\alpha$ plates in the phase transformation from body-centred cubic to hexagonal close packed, J. Appl. Crystallogr. 28 (1995) 571-576

58. D. He, J.C. Zhu, S. Zaefferer, D. Raabe, Y. Liu, Z.L. Lai, X. W. Yang, Influences of deformation strain, strain rate and cooling rate on the Burgers orientation relationship and variants morphology during $\beta \rightarrow \alpha$ phase transformation in a near $\alpha$ titanium alloy, Mater. Sci. Eng. A 549 (2012) 20-29

59. Y.-T. Wang, Y. Adachi, K. Nakajima, Y. Sugimoto, Quantitative three-dimensional characterization of pearlite spheroidization, Acta Mater. 58 (2010) 4849-4858

60. N. Vanderesse, E. Maire, M. Darrieulat, F. Montheillet, M. Moreaud, D. Jeulin, Three-dimensional microtomographic study of Widmanstätten microstructures in an alpha/beta titanium alloy, Scr. Mater. 58 (2008) 512-515

61. T. Seshacharyulu, S. Medeiros, W. Frazier, Y. Prasad, Microstructural mechanisms during hot working of commercial grade Ti-6Al-4V with lamellar starting structure, Mater. Sci. Eng. A 325 (2002) 112-125

62. S. Semiatin, T. Bieler, The effect of alpha platelet thickness on plastic flow during hot working of Ti- $6 \mathrm{Al}-4 \mathrm{~V}$ with a transformed microstructure, Acta Mater. 49 (2001) 3565-3573

63. M. Klimova, S. Zherebtsov, G. Salishchev, S.L. Semiatin, Influence of deformation on the Burgers orientation relationship between the $\alpha$ and $\beta$ phases in Ti-5Al-5Mo5V-1Cr-1Fe, Mater. Sci. Eng. A 645 (2015) 292-297

64. M. Cabibbo, S. Zherebtsov, S. Mironov, G. Salishchev, Loss of coherency and interphase $\alpha / \beta$ angular deviation from the Burgers orientation relationship in a Ti-6Al-4V alloy compressed at $800^{\circ} \mathrm{C}$, J. Mater. Sci. 48 (2012) 1100-1110

65. S. Zherebtsov, G. Salishchev, S. Lee Semiatin, Loss of coherency of the alpha/beta interface boundary in titanium alloys during deformation, Philos. Mag. Lett. 90 (2010) 903-914

66. J. Luo, L. Li, M.-q. Li, Deformation behavior of Ti-5Al-2Sn2Zr-4Mo-4Cr alloy with two initial microstructures during hot working, Trans. Nonferrous Metals Soc. China 26 (2016) 414-422

67. Y. Htwe, K. Kwak, D. Kishi, Y. Mine, R. Ding, P. Bowen, K. Takashima, Anisotropy of $<$ a $>$ slip behaviour in singlecolony lamellar structures of Ti-6Al-4V, Mater. Sci. Eng. A 715 (2018) 315-319

68. A.A. Salem, S.L. Semiatin, Anisotropy of the hot plastic deformation of Ti-6Al-4V single-colony samples, Mater. Sci. Eng. A 508 (2009) 114-120

69. H.-W. Song, S.-H. Zhang, M. Cheng, Dynamic globularization kinetics during hot working of a two phase titanium alloy with a colony alpha microstructure, J. Alloys Comp. 480 (2009) 922-927

70. H.-w. Song, S.-h. Zhang, M. Cheng, Subtransus deformation mechanisms of TC11 titanium alloy with lamellar structure, Trans. Nonferrous Metals Soc. China 20 (2010) 2168-2173

71. B. Xu, X. Wang, J. Zhou, K. Wang, W. Zeng, Research on the microstructure evolution of TC17 titanium alloy during hot deformation, China J Nonferrous Metal 20 (2010) 167-172

72. C.-b. Wu, H. Yang, X.-g. Fan, Z.-c. Sun, Dynamic globularization kinetics during hot working of TA15 titanium alloy with colony microstructure, Trans. Nonferrous Metals Soc. China 21 (2011) 1963-1969
73. T.R. Bieler, S. Semiatin, The origins of heterogeneous deformation during primary hot working of Ti-6Al-4V, Int. J. Plasticity 18 (2002) 1165-1189

74. F. Sun, J. Li, H. Kou, B. Tang, J. Cai, Effect of $\alpha /$ martensite on microstructure refinement after $\alpha+\beta$ isothermal treatment in a near- $\alpha$ titanium alloy Ti60, J. Mater. Eng. Performance 24 (2015) 1945-1952

75. M. Mazurski, G. Salishchev, Effect of interface energy anisotropy on thermal stability and transformation of lamellar Structures: II. Transformation of lamellae, Phys. Stat. Solidi (b) 188 (1995) 653-658

76. H. Dong, J.-c. Zhu, Z.-h. Lai, L. Yong, X.-w. Yang, Z.-s. Nong, Residual elastic stress-strain field and geometrically necessary dislocation density distribution around nanoindentation in TA15 titanium alloy, Trans. Nonferrous Metals Soc. China 23 (2013) 7-13

77. A.J. Schwartz, M. Kumar, B.L. Adams, D.P. Field, Electron backscatter diffraction in materials science (Springer, 2000)

78. A.J. Wilkinson, G. Meaden, D.J. Dingley, High-resolution elastic strain measurement from electron backscatter diffraction patterns: new levels of sensitivity, Ultramicroscopy 106 (2006) 307-313

79. A.J. Wilkinson, G. Meaden, D.J. Dingley, High resolution mapping of strains and rotations using electron backscatter diffraction, Mater. Sci. Technol. 22 (2006) $1271-1278$

80. M. Ashby, The deformation of plastically non-homogeneous materials, Philos. Mag. 21 (1970) 399-424

81. U. Kocks, H. Mecking, Physics and phenomenology of strain hardening: the FCC case, Prog. Mater. Sci. 48 (2003) $171-273$

82. T. Ohashi, Finite-element analysis of plastic slip and evolution of geometrically necessary dislocations in fcc crystals, Philos. Mag. Lett. 75 (1997) 51-58

83. S. Semiatin, J. Brown, T. Brown, D. DeLo, T. Bieler, J. Beynon, Strain-path effects during hot working of Ti-6Al-4V with a colony-alpha microstructure, Metal. Mater. Trans. A 32 (2001) 1556-1559

84. A.M. Zhao, H. Yang, X.G. Fan, P.F. Gao, R. Zuo, M. Meng, The flow behavior and microstructure evolution during $(\alpha+\beta)$ deformation of $\beta$ wrought TA15 titanium alloy, Mater. Des. 109 (2016) 112-122

85. X. Fan, H. Zheng, Y. Zhang, Z. Zhang, P. Gao, M. Zhan, J. Liu, Acceleration of globularization during interrupted compression of a two-phase titanium alloy, Mater. Sci. Eng. A 720 (2018) 214-224

86. R. Quey, J.H. Driver, P.R. Dawson, Tracking the in-grain orientation spreads in hot-deformed polycrystalline aluminium: experiment and finite element simulation, Mater. Sci. Forum (2012) 261-264

87. R. Quey, D. Piot, J.H. Driver, Microtexture tracking in hotdeformed polycrystalline aluminium: comparison with simulations, Acta Mater. 58 (2010) 2271-2281

88. R. Quey, J. Driver, Microtexture tracking of sub-boundary evolution during hot deformation of aluminium, Mater. Character. 62 (2011) 1222-1227

89. S. Dancette, A. Browet, G. Martin, M. Willemet, L. Delannay, Automatic processing of an orientation map into a finite element mesh that conforms to grain boundaries, Model. Simul. Mater. Sci. Eng. 24 (2016) 055014 
90. G. Martin, D. Caldemaison, M. Bornert, C. Pinna, Y. Bréchet, M. Véron, J. Mithieux, T. Pardoen, Characterization of the high temperature strain partitioning in duplex steels, Exp. Mech. 53 (2013) 205-215

91. C. Pinna, Y. Lan, M.F. Kiu, P. Efthymiadis, M. LopezPedrosa, D. Farrugia, Assessment of crystal plasticity finite element simulations of the hot deformation of metals from local strain and orientation measurements, Int. J. Plasticity 73 (2015) 24-38

92. H. Sharma, S.M. Van Bohemen, R.H. Petrov, J. Sietsma, Three-dimensional analysis of microstructures in titanium, Acta Mater. 58 (2010) 2399-2407

93. L. Salvo, P. Cloetens, E. Maire, S. Zabler, J.J. Blandin, J.-Y. Buffière, W. Ludwig, E. Boller, D. Bellet, C. Josserond, $\mathrm{X}$-ray micro-tomography an attractive characterisation technique in materials science, Nucl. Instrum. Methods Phys. Res. Sect. B 200 (2003) 273-286

94. H.F. Poulsen, S.F. Nielsen, E.M. Lauridsen, S. Schmidt, R. Suter, U. Lienert, L. Margulies, T. Lorentzen, D. Juul Jensen, Three-dimensional maps of grain boundaries and the stress state of individual grains in polycrystals and powders, J. Appl. Crystallogr. 34 (2001) 751-756.

95. S. Zaefferer, S. Wright, D. Raabe, 3D-orientation microscopy in a FIB SEM: a new dimension of microstructure characterization, Microsc. Microanal. 13 (2007) 1508-1509
96. J. Konrad, S. Zaefferer, D. Raabe, Investigation of orientation gradients around a hard Laves particle in a warm-rolled Fe3Al-based alloy using a 3D EBSD-FIB technique, Acta Mater. 54 (2006) 1369-1380

97. W. Kaixuan, Z. Weidong, Z. Yongqing, Z. Yigang, Modelling the quantitative correlation between the microstructure and mechanical properties in titanium alloys, Rare Metal Mater. Eng. 40 (2011) 784-787

98. Z. Ji, H. Yang, H. Li, Predicting the effects of microstructural features on strain localization of a two-phase titanium alloy, Mater. Des. 87 (2015) 171-180

99. G. Rogl, S. Ghosh, L. Wang, J. Bursik, A. Grytsiv, M. Kerber, E. Bauer, R.C. Mallik, X.-Q. Chen, M. Zehetbauer, Half-Heusler alloys: Enhancement of ZT after severe plastic deformation (ultra-low thermal conductivity), Acta Mater. 183 (2020) 285-300

100. P. Mansoor, S. Dasharath, Microstructural and mechanical properties of magnesium alloy processed by severe plastic deformation (SPD)-A review, Materials Today: Proceedings (2019)

101. K. Bartha, A. Veverková, J. Stráský, J. Veselý, P. Minárik, C. Correa, V. Polyakova, I. Semenova, M. Janeček, Effect of the severe plastic deformation by ECAP on microstructure and phase transformations in Ti-15Mo alloy, Mater. Today Commun. (2019) 100811

Cite this article as: Jian Zhang, Hongwei Li, Mei Zhan, Review on globularization of titanium alloy with lamellar colony, Manufacturing Rev. 7, 18 (2020) 